\title{
Probing the Los Angeles Basin-Insights Into Ground-Water Resources and Earthquake Hazards
}

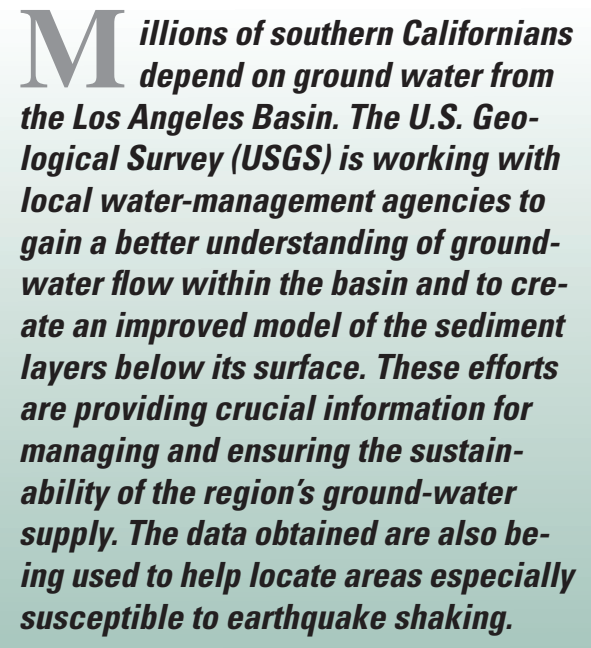

More than 10 million people live in the Greater Los Angeles metropolitan area. Much of this population depends on water pumped from beneath the surface of the Los Angeles Basin. For example, one-third of the water consumed by the 4 million residents in the central and west coast basins is ground water. Successful management of this ground-water resource requires knowing where and how fast the water moves in the various layers of sediment that fill the basin.

Since 1995, the U.S. Geological Survey (USGS) has been working with the Water Replenishment District of Southern California in a cooperative ground-water and geologic study of the Los Angeles Basin. Now, with additional support from the Los Angeles County Department of Public Works, the USGS is expanding this program to study the distribution and geologic history of sediments as deep as 1,500 feet (450 meters) below city streets. This information is critical not only to ground-water management but also to earthquake hazard assessment in the densely populated region. During a strong earthquake, ground shaking may cause water-saturated sediment to "liquefy," resulting in ground failure. Therefore, knowing the composition of near-surface sediment is important for assessing the vulnerability of buildings to liquefaction and other damaging effects of earthquakes.

The USGS has already drilled more than 30 monitoring wells throughout the Los

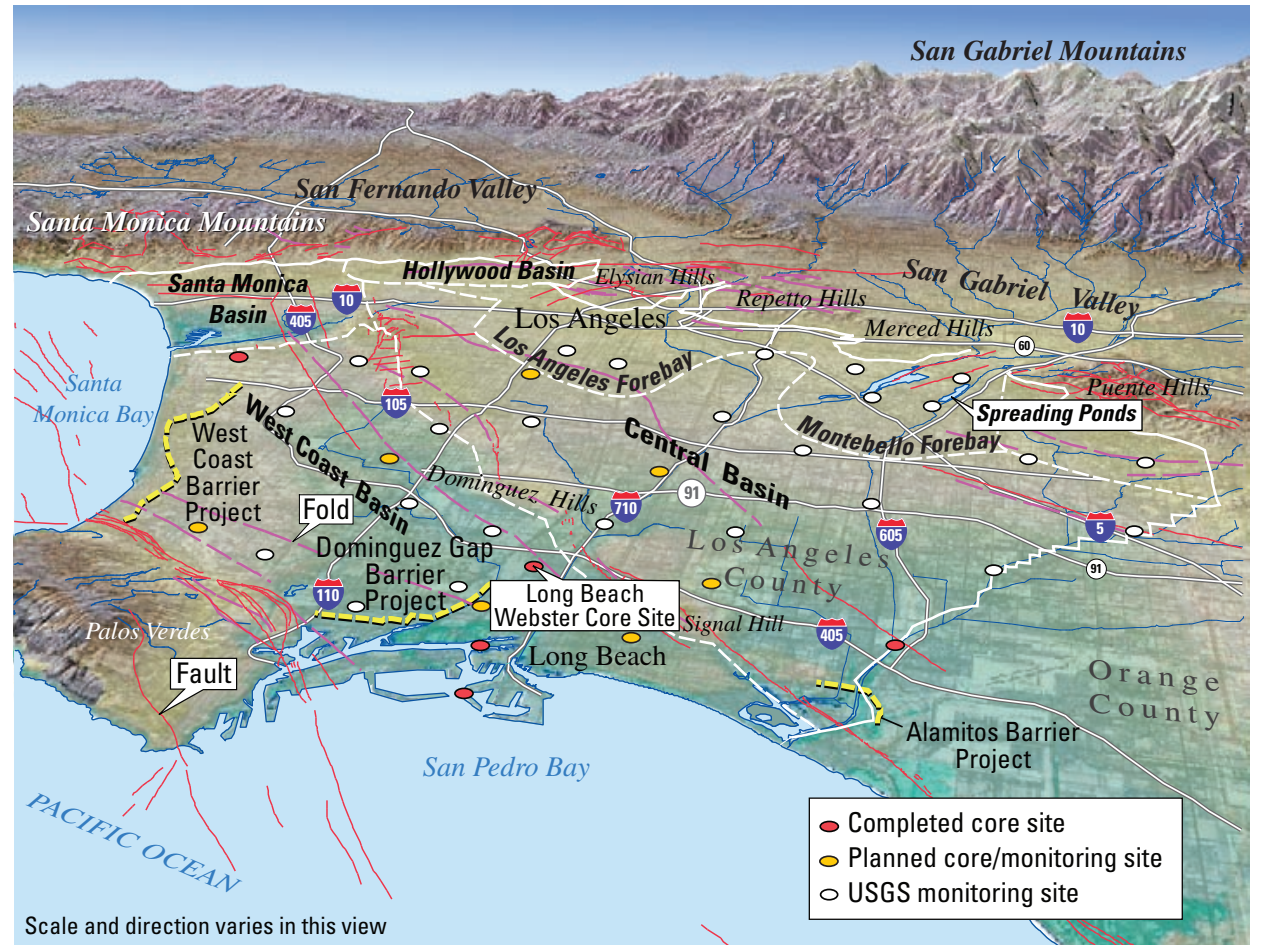

Greater Los Angeles depends on ground water for much of its water supply. As part of a cooperative project with local water-management agencies to better understand the ground-water system and geology of the Los Angeles Basin, the U.S. Geological Survey has drilled more than 30 monitoring wells. Critical issues being examined include the transport and fate of recharge water infiltrated into the ground-water system from spreading ponds in the Montebello Forebay (an area where surface water easily infiltrates the ground) and saltwater intrusion into freshwater aquifers along the coast. In an effort to halt saltwater intrusion, barriers (yellow lines) consisting of arrays of freshwater injection wells have been installed by local water-management agencies.

Angeles Basin and has collected chemical, geologic, hydrologic, and geophysical data from these and other wells in the region. One critical issue being examined is seawater intrusion into freshwater aquifers along the coastal parts of the basin. Another such issue is the transport and fate of water diverted into spreading ponds in the Montebello Forebay, an area of the basin where the underlying sediment is relatively coarse and clay poor and so allows surface water to infiltrate into and recharge the ground-water system.

Ideally, when the monitoring wells are drilled in the Los Angeles Basin, attempts are made to recover intact sediment cores from the full length of a well. Because drilling is costly, large parts of the basin must be explored by other means. Geophysical techniques, such as seismic imaging and gravity surveys, are used to interpolate the character of sediments between wells. Geologic mapping of surface deposits in the basin provides clues to what lies beneath. In harbors and offshore areas, geologic structure below the water surface is revealed by using a ship-towed system that probes the sediments with acoustic pulses. The data obtained using this range of techniques help to characterize the three-dimensional geologic structure and ground-water flow system of the basin.

The present distribution of gravel, sand, and clay in the Los Angeles Basin reflects the interplay between the seashore processes and streams carrying sediment from the upland areas surrounding the basin. Similar processes operated in the past; therefore, knowing the geologic history of changes in sea-level, climate, and rivers allows prediction of the distribution of subsurface sediments in the basin and their possible effects on the regional ground-water flow and seismic hazards. 


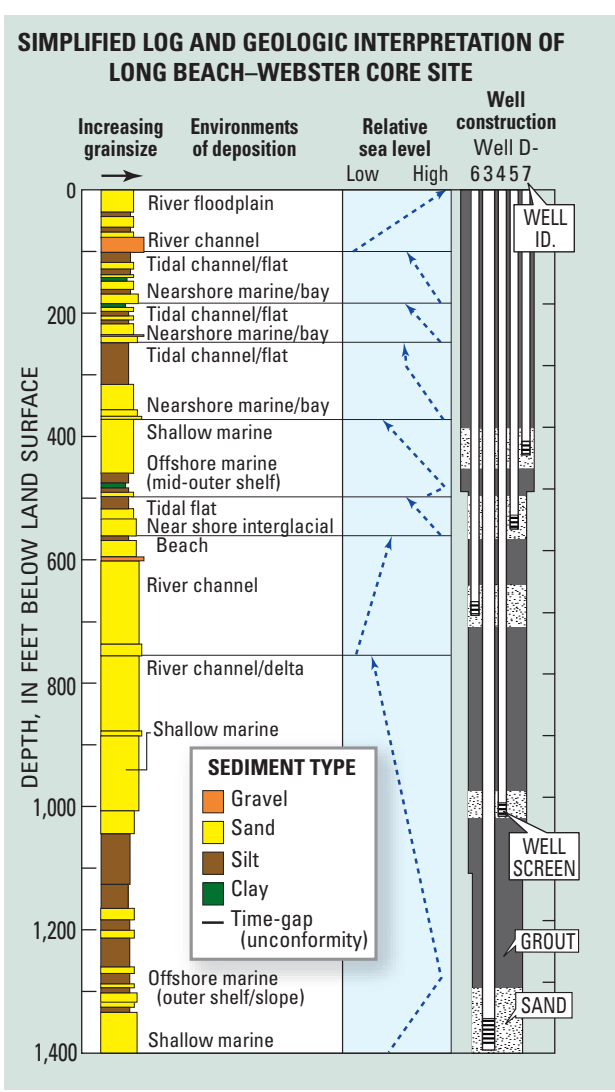

In the cores recovered in the Los Angeles Basin so far, several past cycles of advance and retreat of the sea have been identified. Each cycle leaves a signature in the sediments by producing distinctive layering or bedding, evidence of erosion, and telltale assemblages of fossils. Preliminary age determinations of core samples indicate a correlation of these cycles with the sea-level changes that occurred in the past as a result of the storing and release of vast quantities of water during alternating glacial periods ("ice ages") and intervening warm periods.

An example of how sediments can be interpreted to reveal past conditions was provided during recent drilling of a USGS water-monitoring well in the City of Long Beach. Shells
Sediment cores collected during the drilling of monitoring wells by the U.S. Geological Survey (USGS) in the Los Angeles Basin (see photo) provide information that is vital to understanding ground-water flow and seismic hazards in the region. Scientists study and sample the cores in a USGS mobile laboratory. This diagram shows various types of information obtained from study of cores from a single well. Shown are the thickness and grain size of sediment layers down the length of the well; environments of deposition, such as river channels and tidal flats, interpreted from fossils and other features; changing trends of the height of the depositional surface relative to sea level (blue dashed arrows), and location of well screens that enable sampling of water-bearing layers.

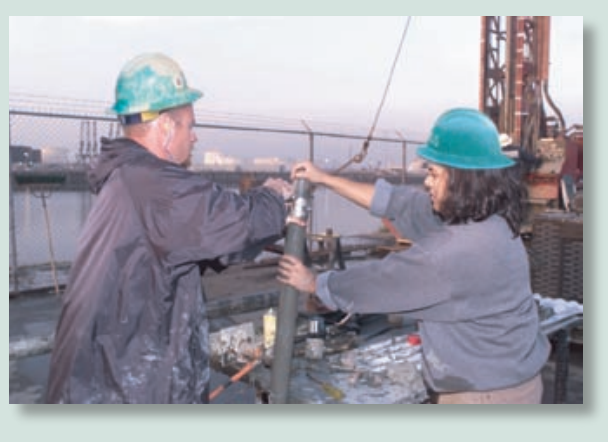

and thick pieces of wood were discovered in coarse sand at a depth of 400 feet (120 meters). This sediment layer, although found hundreds of feet below the surface and several miles inland from the present shoreline, is an ancient beach deposit and has been dated at about 300,000 years old. This date correlates to a high stand of sea level during a warm period between ice ages. The ancient beach is now well below the current ground surface because the Los Angeles Basin has subsided with time as it filled with sediment.

Much information has already been collected in the ongoing study of the Los Angeles Basin. To evaluate the potential effects of alternative strategies for water management, USGS scientists are using these data to develop

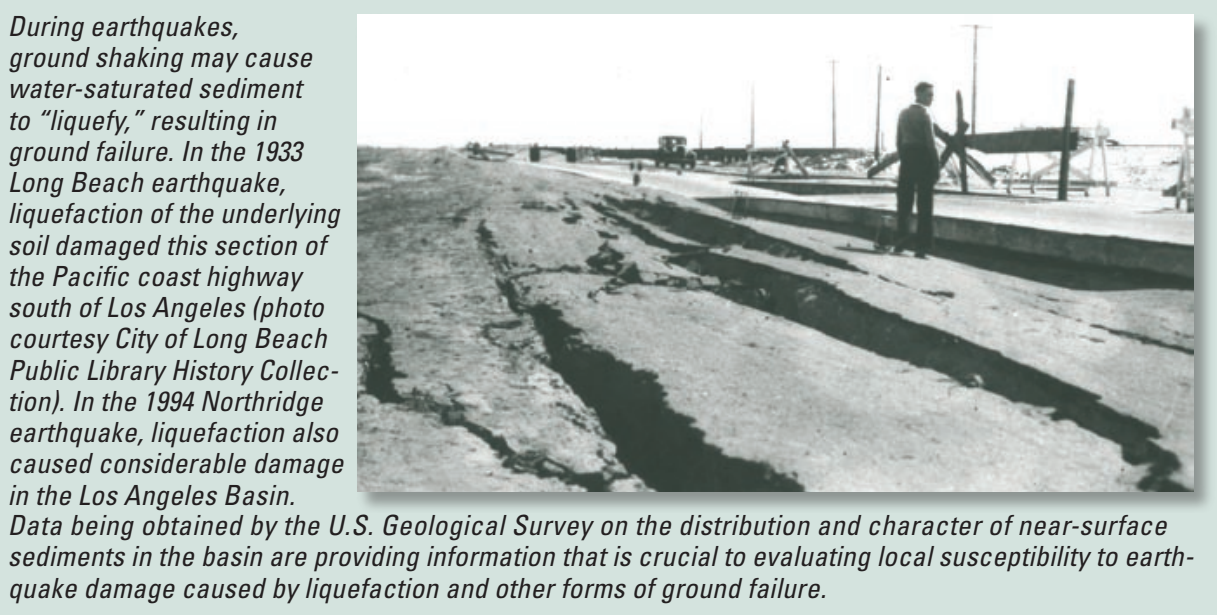

a computer simulation of ground-water flow in the basin. In addition, to further evaluate the ground-water resource, as well as earthquake hazards, the scientists are using the data to develop a model of the three-dimensional geology of the basin. This model includes ages, thicknesses, grain sizes, and environments of deposition of sedimentary beds; locations and quality of water-bearing zones; and locations of major fractures and faults. This geologic model will incorporate the concept of "sequence stratigraphy," which recognizes the influence of climate-driven depositional cycles on the distribution of sediment types.

During the next several years, the USGS will be drilling and coring more wells in the Los Angeles Basin and applying geologic and ground-water models to address a host of practical questions for the region: What are the main pathways for seawater intrusion? What are the best strategies for recharging the ground-water supply, such as pumping, injecting, and spreading water? Where are faults located underground and what earthquake hazards do they pose? Which areas face greater risks to life and property during earthquakes because they are more likely to experience intensified shaking or soil liquefaction?

The cooperative efforts of the USGS, the Water Replenishment District of Southern California, and the Los Angeles County Department of Public Works are providing a better understanding of the ground-water system and geology of the Los Angeles Basin. This knowledge is essential to ensuring future adequate ground-water supplies for this populous urban region and to mitigating the threat posed by earthquakes.

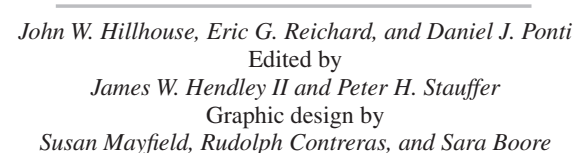

COOPERATING ORGANIZATIONS

Water Replenishment District of Southern California Los Angeles County Department of Public Works

For more information contact:

Ground Water - Eric Reichard (858) 637-6834

U.S. Geological Survey

5735 Kearny Villa Road

San Diego, CA 92123

e-mail: egreich@usgs.gov

Earthquake Hazards - Daniel Ponti (650) 329-5679

U.S. Geological Survey MS 977

345 Middlefield Rd.

Menlo Park, CA 94025

e-mail: dponti@usgs.gov

See also Saltwater Intrusion in Los Angeles Area

Coastal Aquifers - The Marine Connection (USGS Fact Sheet 030-02).

This fact sheet and any updates to it are available online at:

http://geopubs.wr.usgs.gov/fact-sheet/fs086-02/ 